\title{
Robots and Cultural Heritage: New Museum Experiences
}

\author{
Claudio Germak \\ Politecnico di Torino, \\ Turin, Italy. \\ claudio.germak@polito.it \\ -----
}

\author{
Maria Luce Lupetti \\ Politecnico di Torino, \\ Turin, Italy. \\ maria.lupetti@polito.it
}

\author{
Luca Giuliano \\ Politecnico di Torino, \\ Turin, Italy. \\ luca.giuliano@polito.it
}

\author{
Miguel E. Kaouk Ng \\ Politecnico di Torino, \\ Turin, Italy. \\ miguel.kaoukng@polito.it
}

\section{ABSTRACT}

The introduction of new technologies to enhance the visiting museum experience is not a novelty. A large variety of interactive systems are nowadays available, including virtual tours, which makes cultural heritage accessible remotely. The theme of increase in accessibility and attractiveness has lately been faced with the employment of the service robotics, covering various types of applications. Regrettably, many of robotics solutions appear less successful in terms of utility and usability. On the basis of this awareness, a design for a new robotic solution for cultural heritage has been proposed. The project, developed at the royal residence of Racconigi Castle, consists of a telepresence robot designed as a tool to explore inaccessible areas of the heritage. The employed robot, called Virgil, was expressly designed for the project. The control of the robot is entrusted to the museum guides in order to enhance their work and enrich the cultural storytelling.

\section{KEYWORDS}

Service robotics; Robo-ethics; Service design; Human centred design.

\section{I INTRODUCTION}

In the 17th century, the magic lantern technology, a projection system, which was the forerunner of the cinema, was used mostly in the earliest forms of museum, the Wunderkammer, to make visits more attractive and engaging.

Nowadays, four centuries later, visitors interact with the museum contents via multimedia systems and technologies (projection, hologram, app, robot, etc.) and in a variety of ways (touch, free actions, voice), either on-site or remotely (Ippoliti, 2011). This helps expand access to museums, pursuing the Laws and Agreements for Cultural Heritage, as initiated by the first declaration of the Italian Franceschini Commission (1967): "The actions of conservation, defence and enhancement of cultural heritage are all founded on the social function that is achieved as long as the most extensive public use is guaranteed" (Ippoliti, 2011).

An increasing trend in the fruition of museums is also represented by virtual tours, based on the same concept of wide accessibility. Virtual tours, indeed, aim to make the cultural heritage visible for remote 
cultural activities, such as study and research, to encourage people to visit the museum and to give them a preview of the location. The most popular example is, probably, represented by Google Art Project (Proctor, 2011), a sort of repository of digitalised masterpieces and museums from all over the world. Through the web, people are able to navigate autonomously into realistic environments that reproduce famous galleries and museums combining 3D modelling and HD pictures. It is also possible to zoom on artworks and observe details undetectable by human eyes. It is possible to recognise different typologies of virtual tour, each one offering a slightly different functionality, on the basis of the technological orientation. The affordance, combined with the effectiveness of the technology applied, determines the usability and the consequent adoption of the service (Salvini et al., 2010). With regard to this, Sylaiou at al. (2014) conducted a usability evaluation study of these different typologies, evaluating their quality on the basis of the indications of the ISO-9241, which relates to the usability and ergonomic requirements of interfaces (ISO, 2011). The evaluation is mainly based on five parameters, namely: ease of learning, efficiency of use, ease to remember, fault tolerance and pleasantness of use. From this analysis arises the fact that the effectiveness of a virtual museum is related to its ability to offer the visitors an experience rich of features, but most of all, imageability, navigability, interactivity and narration (Sylaiou et al., 2014). Indeed, people largely appreciate the ability to explore freely the virtual museum, choosing when and where to deepen, whereas a low quality of the displayed environment leads to disengagement. The employment of virtual museums, even if it aims to increase accessibility and attraction of the museum, in some cases could lead to the opposite result. As stated by the London Charter, this kind of solutions has to be employed when they can provide additional value in comparison with other methods (Beacham et al., 2006).

In this sense, a new frontier is represented by service robotics. Features common in robotics applications, such as connectivity, abilities of interaction, autonomous movement, people and object recognition, enable new ways to face the recurrent themes of Cultural Heritage innovation, such as remote exploration, increase of the accessibility, attraction and the improvement of the user experience.

\section{I METHODOLOGY}

This paper, therefore, discusses the remote fruition experiences of museums, with particular reference to service robotics for the development of a new museum experience. In particular, the research concerns a project developed at the Residences of the Royal House of Savoy in Piedmont (Italy).

\subsection{DOMAIN ANALYSIS}

The first part of the research is dedicated to related work, an overview of international case studies analysis assessed by looking at the quality achieved by the design of the service referring to the parameters indicated by the ISO-9241. The strengths and weaknesses of the two types of virtual tour, onsite and remote, are analysed, assessing the degree of empathy created between the visitor and the museum. The museum, indeed, is not just a collection of artworks, but rather embedded in a physical and emotional context (Suchy, 2006), in which it is fundamental not to lose the perception of details compared to the whole. The main challenges for technical system design rely on the contrast between light and darkness, on the scent of the materials and the difference between noisy and silent areas. For this reason, we have developed a deepened scenario analysis, in which both physical aspects of the context and human activities have been taken into account. From the scenario analysis, with a special focus on ethical aspects, resulted requirements that guided the development of the robotic service concept. The project includes also a product design phase, in which the robot Virgil has been designed. This phase describes both the hardware and software used to define the prototype framework and the aesthetic features that have been chosen.

\subsection{RELATED WORK}

The use of robots in museum context is not a novelty. Indeed, there is a large scientific literature about it. Since now, the robots were used mainly in three modalities: museum guide, telepresence and installation.

Definitely, the robotic museum guide category is the most common and includes applications from all over 
the world. These robots are all characterised by the ability of autonomous navigation, obstacle detection and verbal interaction with visitors to describe the contents of the museum.

Already in 1998, at the Carnegie Museum of Natural History in Pittsburgh, has been introduced the use of a robot, named Chips at first and Sage later (Nourbakhsh et al., 1999), to accompany visitors in the Dinosaur Hall and to give audiovisual information about it (Willeke et al., 2001), provided to the user as a unidirectional narrative speech (Nourbakhsh et al., 1999). Subsequently, in the same museum, other robots were introduced with the same purpose (Willeke et al., 2001).

In the following year, the Smithsonian's National Museum of American History introduced the robot Minerva, which gave tours to tens of thousand of visitors (Thrun et al., 1999). This robot was equipped with a moving head able to produce facial expressions and communicate its emotional state, defined in accordance to the people's behaviour. These expressive skills improved the attractiveness of the robot and the effectiveness in the guidance (Thrun et al., 1999).

The common and central problem of the effectiveness of speech interaction has been faced in the CiceRobot project, tested at the Archaeological Museum of Agrigento, in Italy. In this case the robot, entrusted of the guide activity, allows visitors to make questions. In order to improve the adaptation of the speech and the coherence of the answer, the robot cognitive architecture has been provided of a semantic module that filters the information received by listening to visitors' questions. (Macaluso et al., 2005).

In 2000, a group of three different robots have been introduced at the Museum für Kommunikation, Berlin. These three robots were entrusted of different duties: instruction, incitation and entertainment. The instructive robot was, indeed, a museum guide that accompanied visitors in the tour giving explanations about the exhibit. It was able to move the head up and down to indicate which object it was referring to and also it was provided with a screen on which it could show additional contents (Schraft et al., 2001).
From the engagement and effectiveness points of view, an interesting step forward is represented by the case of Urbano. This guide robot, employed in different exhibition spaces around Spain, was able to show emotional behaviour (Alvarez et al., 2010), in addition to facial expressions. Its behaviour was adapted on the base of the visitor's behaviour, in order to modulate the rhythm with which it gives information, and consists of three main emotional states: afraid, happy and curious (Alvarez et al., 2010).

Recently, one of the world's most advanced humanoid robots, Asimo, has been tested as museum guide at the Japan's National Museum of Emerging Science and Innovation (Falconer, 2013). The basic purpose was the same of the previous project, but in this case there was a particular attention to the interaction with a group of people. For example, in order to understand whom from the group is asking a question, it suggests people to raise a hand. Unfortunately, this feature, and others, was still not working as it was supposed to and the overall experience resulted negative from the engagement point of view (Falconer 2013).

Probably, the category that is witnessing the wider expansion is the one of telepresence robots. They are connected to the web and allow visitors to explore the museum remotely. In general, these are all mobile robotic platform equipped with a screen and a camera. The use of this kind of robots is applied with different purposes.

The robot Csiro, for example, has been introduced at the National Museum of Australia, in order to allow people, which are unable to reach the museum, e.g. students from rural areas of Australia or the aged in nursing homes, to visit it anyway (CSIRO, 2015).

The robot Norio, from Droids Company (Droids Company, 2015) instead, was designed to allow people with limited mobility, e.g., wheelchair users, to visit a museum, which would otherwise be impervious for them. This robot was placed, and is still working, at the National Centre for Monuments, Château d'Oiron, France. At the ground floor of the museum is a cockpit from which the visitor can remotely drive the robot located at the first floor (Oiron, 2015). Another interesting example is the After Dark project, which involved the Tate Britain, in London (Tate, 2015). The 
concept of the project is to allow people to explore the museum rooms during the night, playing with the sense of prohibition and exploiting the charm that this place assumes during the night. During this experience, available for five nights, in August 2014, some people, chosen randomly, have been connected, via Internet, to the four robots placed in the museum and drove them via computer (Tate, 2015).

The installation category is mostly art-oriented and the robotic technologies that are part of it, are generally embedded in an artistic or educative setup. One example is the TaraScope, an educative installation that enables groups of students to interact from a space observatory in Ireland with a robotic telescope located in San Francisco, California (Hogan et al., 2015). The installation comprises tangible interfaces and digital displays. The artist and scientist Patrick Tresset, developed a robotic art installation called Paul. This installation, exhibited at Tenderpixel Gallery in London for the first time in 2011, consists of a left hand robotic arm holding a black biro and a pan-tilt camera, both bolted to a table in front of which is located a chair for visitors (Tresset et al., 2012).

These three types of museum robotic applications have been empirically evaluated (Figure 1) on the base of the parameters indicated by the ISO-9241 (ISO 2011). Specifically, these parameters are meant to evaluate the quality of the interaction.

The interaction with guide robots, indeed, appears easy to learn and to remember, due to the fact that it is based on natural interaction modalities, such as speech, facial expressions, gestures and proxemics. On the other hand, this kind of solutions frequently produces errors (Falconer, 2013), which, in addition to the low adaptability of the tour, causes a poor efficiency and, consequently, not much pleasantness to use.

Telepresence robots, instead, achieve a higher level of use efficiency and the interaction is easy to learn and remember, due to the adoption of a mediating interface familiar to the users. The robot control, as a matter of fact, occurs through a computer or a tablet, and the control consists of tele-operation, ability that most of people have experienced at least in childhood. These aspects, thus, determine a higher level of use pleasantness.

Regarding the robotic installations category, it is not possible to make absolute considerations.

Nevertheless, it is possible to assume that the easiness of use and remembrance are common as well as the pleasantness. The error production and the efficiency, instead, are the most variable aspects
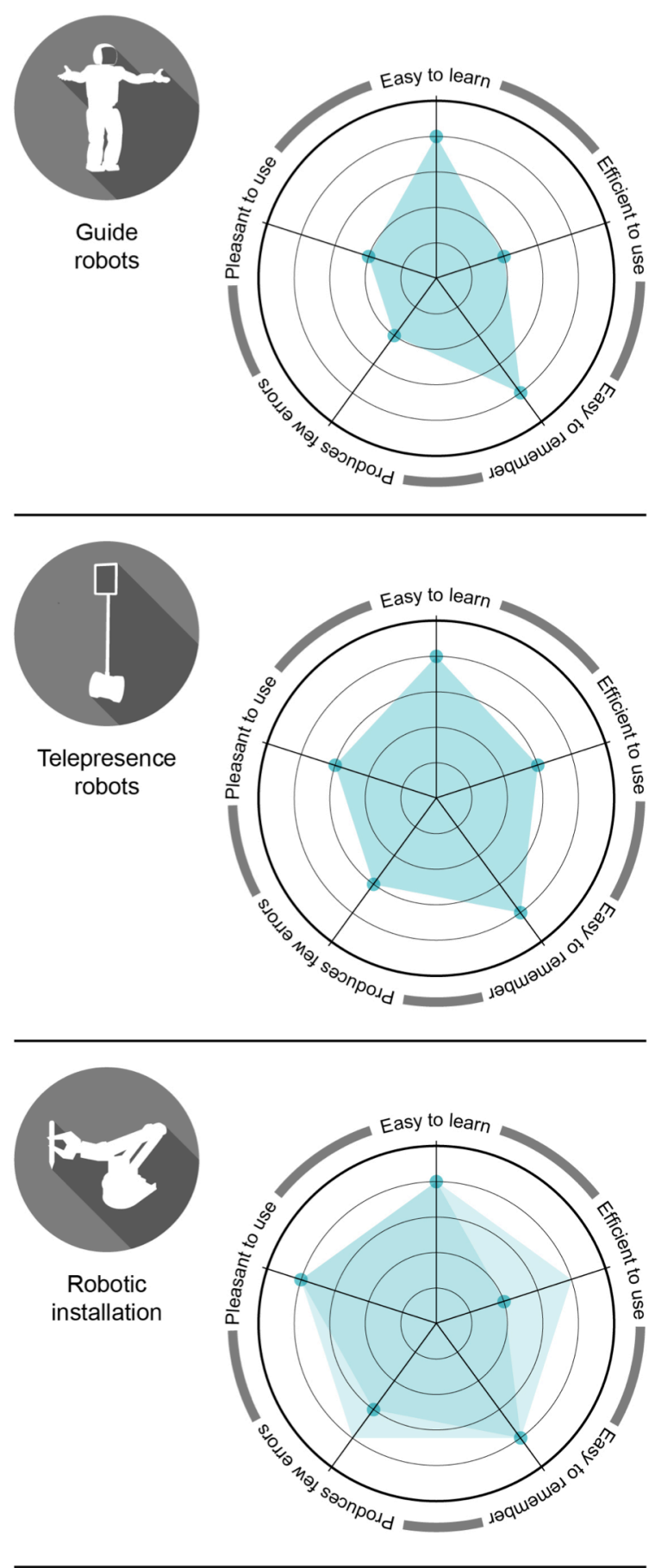

Figure 1 | Empirical usability evaluation of the three main categories of museum robotics. 
from project to project.

From these considerations emerges the fact that, in most of cases, robots are utilized in museums regardless the evaluation of the physical aspects of the context and the human activities which are carried out there.

\section{I VIRGIL: NEW ROBOTIC MUSEUM EXPERIENCE}

Virgil (Germak, 2015) is a telepresence robot, which represents the results of a project for the enhancement of Cultural Heritage and improvement of the fruition experience. This project has been developed for a specific museum context: the royal residence of Racconigi Castle, in Piedmont, Italy. This castle, called over time as villa of delights, was a holiday residence of the Savoy royal family. It is a surprisingly rich context but, simultaneously, extremely delicate. All the Cultural Heritage, indeed, are places to which are entrusted two main activities: the preservation and fruition (Barile et al., 2012). Regrettably, in some cases these two activities are mutual exclusive. For this reason, at Racconigi, some rooms of the residence are currently excluded from the visit tour mainly because of the state of conservation, fragility and logistic management of the visit. It has been estimated that more than $60 \%$ of the residence remains inaccessible to visitors during a standard guided tour.

This phenomenon, in which part of the cultural heritage remains hidden, does not only concern the Racconigi Castle, but it is diffused throughout Italy. However, in most cases the main concern relates to the fact that a large amount of artworks and artefacts remains closed in the archives, whereas the problem of areas excluded from the tour route is not widely addressed.

For example, many newspapers and journals highlight this issue of hidden artworks that would represent an asset to be exploited (Pirrelli, 2012). These kinds of statements are confirmed by the Istat (National Institute for Statistics) reports in which is shown that $31.1 \%$ of museums expose just around the $50 \%$ of the owned goods (Istat, 2013). Further, the delicate nature of the castle influences the visitor tour. The access of visitors is organised in groups of maximum 20 people, mandatorily accompanied by a museum guide or a castle guardian. Therefore, the museum guides assume a central role in the experience of the museum visit and, as is well known, their competences have a strong influence on visitor satisfaction (McDonnell, 2001). The storytelling activity performed by the museum guide comprises three main aspects: selection, information and interpretation. The last one is the aspect that mostly determines the uniqueness of the experience due to the fact that the museum guide uses the interpretation to create a link between the heritage contents and the visitor culture. An effectively interpretative approach, indeed, determines the transference of cultural understanding (McDonnell, 2001).

From these considerations emerge two requirements: make excluded areas accessible to visitors of the residences, and enhance the activity of the museum guides. The proposed service robot meets these requirements, extending the museum tour through a real-time virtual tour, made possible by the Virgil robot placed in inaccessible areas. The museum guide

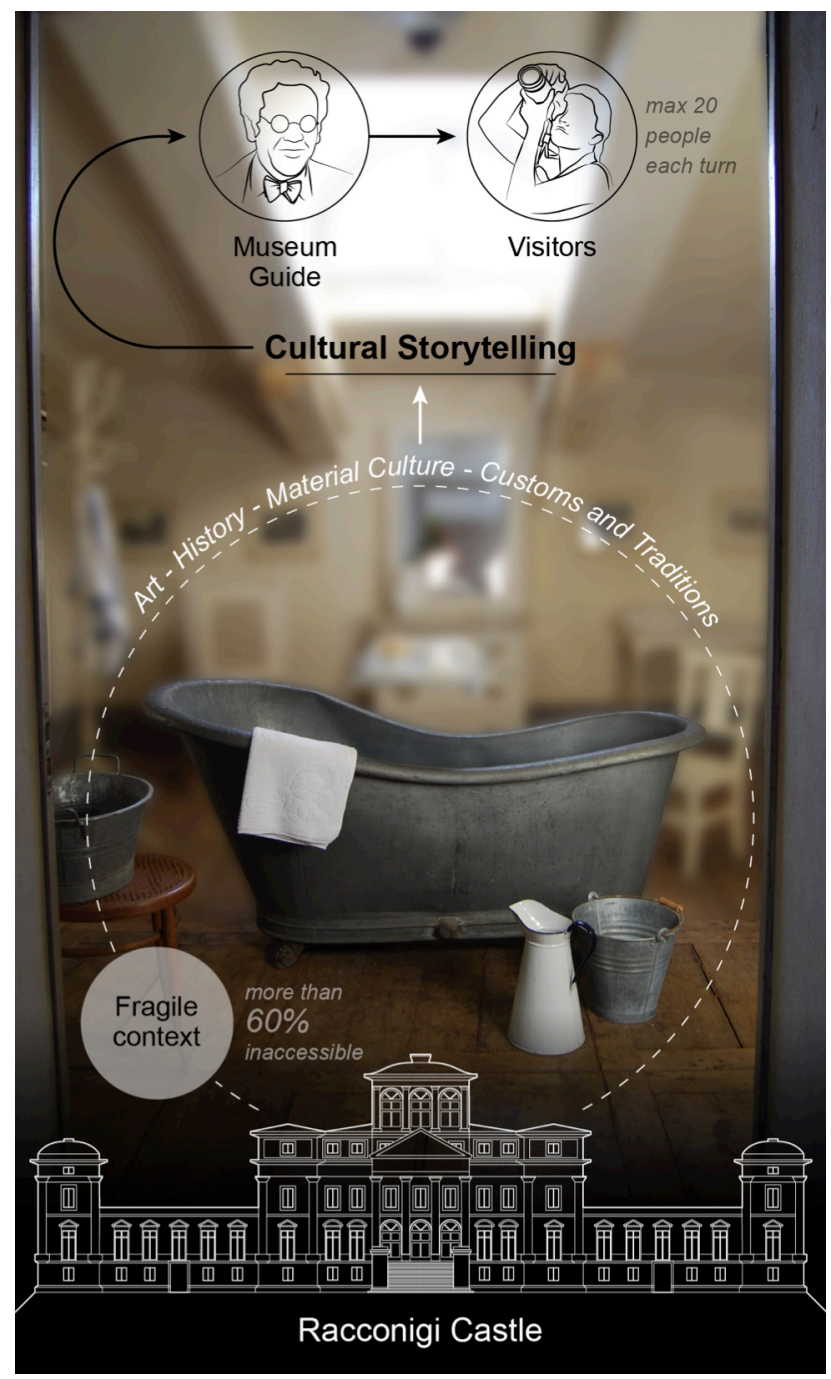

Figure 2 | The Racconigi Castle scenario overview. 
assumes a fundamental role since, in addition to the usual accompanying and deepening role in the fruition of the cultural heritage, he is entrusted of the remote control of the robot.

The new robotic service implements the concept of human-robot collaboration (Epstein, 2015). Conversely to many robotic solution applied in museums, as shown in the related work paragraph, the storytelling activity continues to be entrusted to the museum guide and a robot assumes the role of a remote collaborator, which explore the areas inaccessible for people. Keeping the storytelling activity performed by the museum guide is fundamental due to the fact that only a human can provide the interpretative aspect. The interpretation (McDonnell, 2001), as previously explained, is the process in which the museum guide can create links between the visitor culture and the heritage contents. This process allows visitors to develop an empathic relationship with both the museum guide and the cultural heritage itself.

A further consideration has to be addressed in the comparison of this robotic service with other existing technologies, especially virtual tours. Virtual tours currently seem to be the cheapest and easiest technology available, however it involves considerable limitations in terms of imageability and narration. Even if this solution can achieve a high level of image quality, the visual result is never realistic due to the fact that while navigating through these environments the adaptability of the image and the fluidity of movement are not like the natural. In addition the narrative activity, if entrusted only to multimedia contents, can appear boring, non adaptable and restricted.

\subsection{SOLUTION ARCHITECTURE}

The robot, designed specifically for the project, consists of a mobile robotic platform, equipped with a camera that streams video displayed to visitors on a dedicated screen or on personal devices. The solution exploits a cloud robotics platform (Guizzo, 2011), which ensures the robustness needed for long-term operability and to expose simple APIs to the final user (Ermacora, 2015). The Virgil robot communicates with the Cloud Robotics Platform (CRP) through Long Term Evolution (LTE) technology. The CRP has a central unit called "Robot Clone Manager" (RCM) which takes care of all the jobs necessary to connect user with robot. Basically, RCM manages the information from the robot and sensors and exposes them to the user. At the same time, the framework, receives commands from the user, processes and transmits them to the robot. The user is able to interact with the robot through a Graphical User Interface (GUI), displayed on a PC or on a tablet via a web browser.

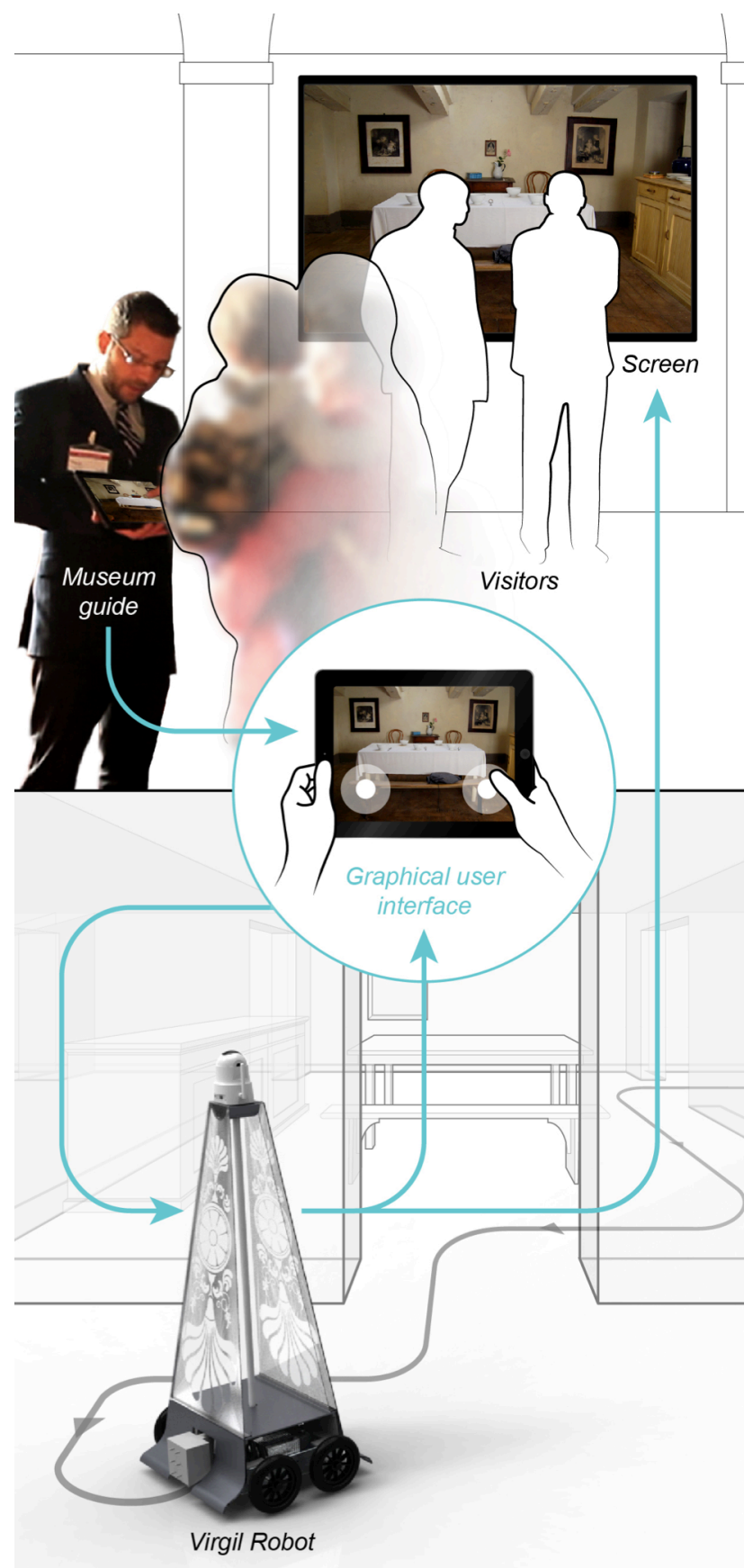

Figure 3 | The new robotic museum experience: general schema of the service. 


\subsection{REMOTE EXPLORATION SERVICE}

The scenario defined during the design process involves the use of a robot tele-operated by the museum guide to explore temporarily inaccessible areas of the castle. The streamed real-time video is presented to the visitors on a dedicated screen. Figure 4 shows the functional architecture of the software designed for this robotic service application.

Starting from the Hardware layer, Laser Driver block is in charge of abstracting the information from the laser scan sensor and sends it to the service layer. The Ray-tracing block converts the Laser Scan data (from polar to Cartesian frame) into a jpeg image in order to understand the occupancy information of the environment close to the robot. Then the Mjpeg Streaming block compresses the images and sends the image stream to ROSBridge, an interface to the robot operating system (ROS) (Quigley at al., 2009). The Obstacle Detection block takes the information from the laser scan sensor and evaluates the nearest obstacles to the robot in three different zones (right, left, centre). It provides this information to the Obstacle Manager to generate the warning signals. The Velocity Manager processes the warning signals and the locomotion commands send by the user in order to provide velocity commands to the robot through the locomotion driver. The Visual Sensor block abstracts the information from the camera and sends it directly to the GUI through RTP (real-time transport protocol) streaming. Finally, ROSBridge provides a Websocket transport layer to connect the service layer with the application layer.

\subsection{ROBOT DESIGN}

Virgil consists of a four wheels drives mobile robot able to move through indoor structured environments. Its mechanical structure is designed in a pyramid shape with a rectangular base of $50 \times 55 \mathrm{~cm}$, a height of $120 \mathrm{~cm}$ and a weight of $10 \mathrm{~kg}$ approx. The choice to set the camera at $120 \mathrm{~cm}$ height is due to the willingness to replicate a point of view similar to the human, in order to allow the visitor to attend a familiar experience and build an empathic bond with the visualized spaces.

The design process was based on specific requirements, namely the robot should be unobtrusive and homogeneous to the context in which it is going

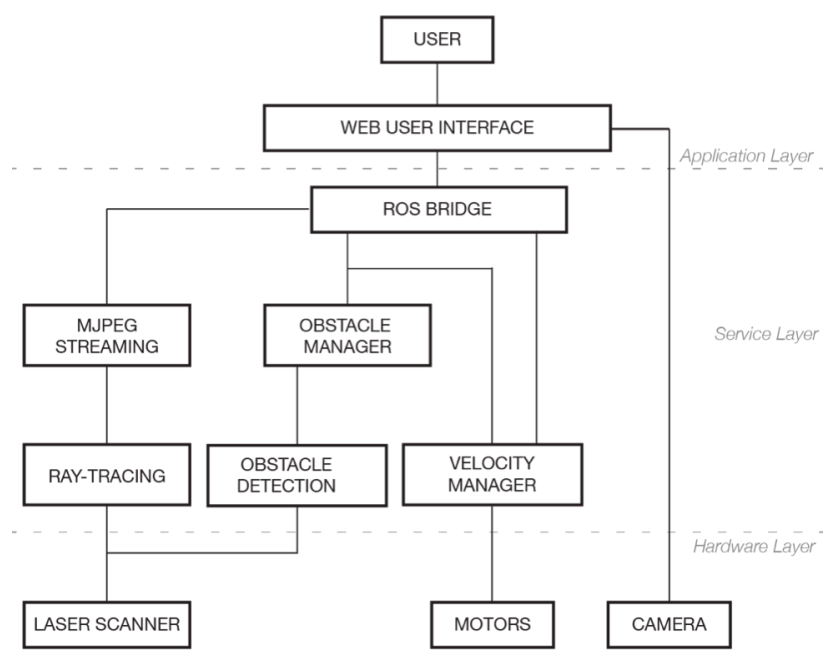

Figure 4 | Software architecture.

to be inserted. This is due to the fact that it is necessary to ensure maximum visibility to the artistic good exhibited in the heritage. For this reason, the cover of the robot is made of PMMA (poly-methylmethacrylate) and is composed in a shape of a truncated pyramid, reminding to the similar shape largely diffused in Savoy tradition, used in obelisks, bollards and other architectural elements or furniture. The choice of transparent material, thus, was lead by willingness to avoid the distraction of the visitors from the cultural goods to the robot and besides to meet a technical requirement of maximum lightness.

Therefore, this solution provides a substantial physical and visual lightness, also in line with the way-finding elements already present in the royal residence. In addition, in the design process the concept of

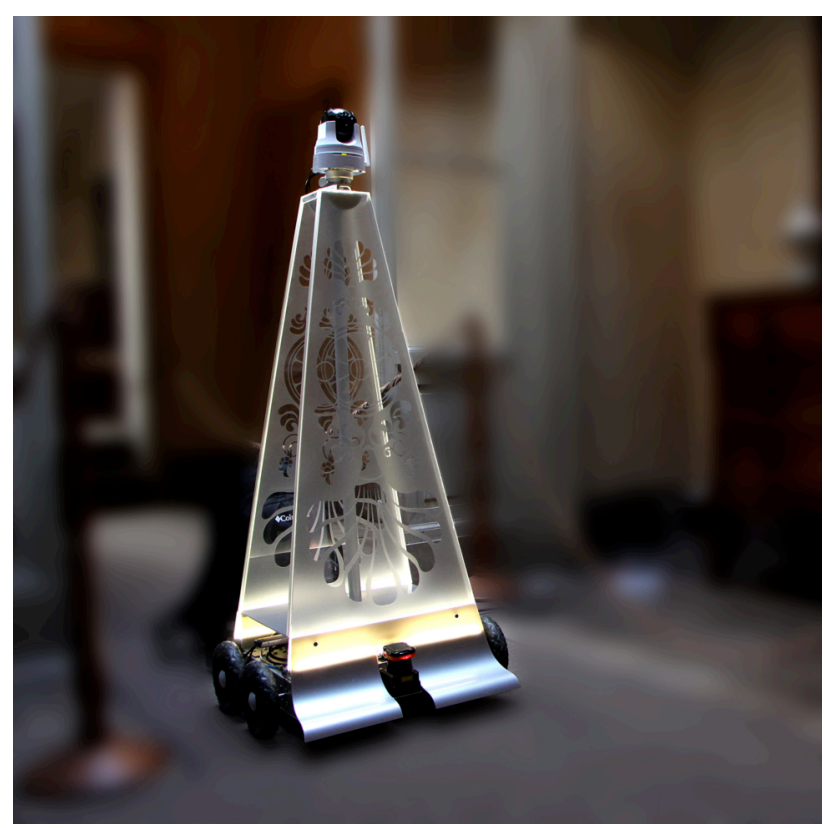

Figure 5 | The Virgil robot. 
customisation based on the context has been introduced, consisting in a decorative pattern applied on the robot coverage. The pattern represents the Palagiana palm, an already existing decorative motif that can be found in the castle applied in many elements, from the floors to the furniture.

\subsection{GRAPHICAL USER INTERFACE (GUI)}

The GUI, that allows the museum guide to interact with the robot via web browser, is currently being redesigned. As shown in Figure 6, it is composed by several elements, namely:

1 - STREAMING VIDEO. This window shows a realtime video stream coming from the camera of the robot.

2 - LASER IMAGE FLOW. This element shows the data received from the laser-scan sensor. Through this image flow, the user can see the obstacles during the tele-operation stages.

3 - TELE-OPERATION BUTTONS. These elements, similar to a control pad, are used to move the robot in the environment.

4 - ASSISTANCE PANEL. This panel consists of various elements that provide information and assistance to the user during teleoperation, such as robot speed (linear and angular).

5 - MAP. This panel provides the user with an overview of the environment in which the robot is moving.

6 - MULTIMEDIA BUTTONS. These buttons allow the activation of the multimedia contents.

\section{I THE ETHICAL APPROACH}

From the beginning, the Virgil project was developed considering ethical aspects as mandatory. Each design choice was made, not just on the basis of technical feasibility, but rather with the evaluation of the alternatives answering to questions such as: is it effectively useful to introduce the robot in this way? Is it preferable to use the robot compared to other technologies? Is the use of a robot fair towards the various stakeholders?

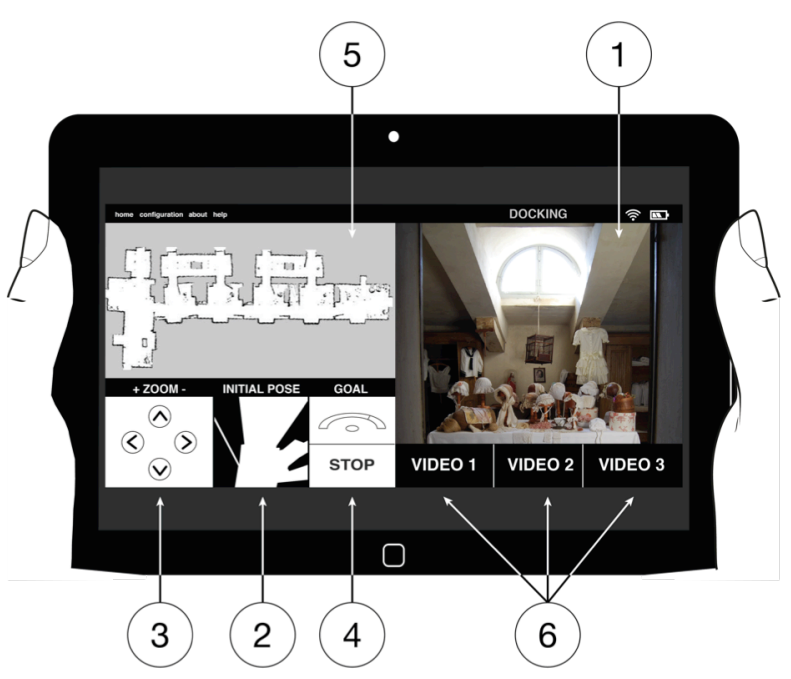

Figure 6 | Draft of the Graphical User Interface.

According to this approach, the ethical dimension of project is achieved by the attempt to ensure respect for both for the location and the various stakeholders.

From the location point of view, the service proposes a possible solution to the issue of inaccessibility of some castle's areas. The concept of widenning the accessibility meets the statements of the Franceschini commission according to which the social fruition of cultural heritage have to be guaranteed for the widest possible audience (Ippoliti, 2011). This is also reaffirmed by the Decree Law no. 112, which states that a Cultural Heritage have to guarantee the full accessibility, physical and intellectual, of its collections, also ensuring the consultation of goods excluded from the exhibition (D. M., 2001).

The service makes the exploration of additional areas of the castle possible even without the need of conducting restoration and safeguarding works. In addition, the proposed solution does not require a fixed implantation to perform the activity. Both the robot and the docking station are movable and this meets the requirement not to overbuild in the context, which is a building structured and evolved over the centuries and, hence, cannot be modified by structural interventions (D. M., 2001).

From the stakeholder's point of view, the project brings benefits to all the actors involved. The visitors, indeed, benefit from the expanded visiting experience, enriched by the additional knowledge about the robotic solution. 
The museum guides, instead, assume a central role in the visiting experience, due to the fact that they are entrusted of both the cultural storytelling and the robot control. This generates an enhancement of human work and additional professionalization. This aspect is particularly crucial since it relates to a widely diffused concern about the introduction of robots. The diffusion of robots in industrial field, indeed, generated a substantial replacement of human work and, consequently, an increase of unemployment (Salvini et al., 2010). The introduction of robotics in other fields raises the concern that the same phenomenon could occur. For this reason, during the design process it is necessary to consider the human work, avoid its replacement and, moreover, enhance it (Bisol et al., 2014).

Finally, the institutions, to which the Cultural Heritage management is entrusted, benefit from the improvement of visibility and attractiveness.

\section{I FUTURE WORK}

In the near future, there will be the first experimental phase with visitors, in which the early data on the experience by the users will be collected. The aims of this experimental phase are to understand the visitor's acceptance of the robotic solution, the perceived quality of the experience and the emotional reactions of the visitors to the additional multimedia contents. These data will be collected through a questionnaire and will be used to improve the user experience and the effectiveness of the solution.

\section{I CONCLUSION}

The improvement of Cultural Heritage fruition is a recurrent theme and has been faced with the application of the most diverse technologies. The exemplary case represented by virtual tours, which offers the opportunity of a remote visiting experience, enabled a wide range of new design opportunities. Nevertheless, the limits of this kind of solutions drove to a deep reflection on the effectiveness of a totally virtual experience.

For this reason, the use of Service Robotics in museums is becoming increasingly common. Robots, indeed, represent a bridge between the virtual and the physical world, due to their composite nature. However, the observation of international case studies of museum robotics has shown that, since now, many of the proposed solutions were not actually meeting the location and stakeholders' requirements, which usually vary on the basis of the context.

Based on this consideration, a new robotic museum experience has been designed, with the aim to increase the museum's attractiveness, to offer a more involving experience to the visitors, and to enhance museum guides activity. The proposed solution was developed paying particular attention to the ethical aspects and is meant to represent a shifting in the robotic design process. The applications of new robotic solutions, indeed, are usually based on the opportunities offered by the technology, whereas this project was developed applying a human centred design approach, which focuses on people instead of technology.

\section{ACKOWLEDGEMENTS}

This project has been developed in collaboration with the Jol CRAB (Connected Robotics Applications laB) of Telecom Italia and the Terre dei Savoia Association, promoters and manager of cultural activity related to Savoy Cultural Heritage, especially at Racconigi Castle.

\section{REFERENCES}

Alvarez, M., Galan, R., Matia, F., Rodriguez- Losada, D., \& Jimenez, A. (2010) An emotional model for a guide robot. IEEE Transaction on Systems, Man, and Cybernetics - Part A: System and Humans, Vol. 40, No. 5, September.

Barile, S. \& Saviano, M. (2012) From the management of Cultural Heritage to the governance of Cultural Heritage system (in Italian). Patrimonio culturale e creazione di valore, Verso nuovi percorsi, Cedam.

Beacham, R., Denard, H., \& Niccolucci, F. (2006) An introduction to the London charter. The E- volution of the ICTechnology in Cultural Heritage, Joint Event CIPANAST/EG/EuroMed Event.

Bisol, B., Carnevalle, A., \& Lucivero, F. (2014) Human rights, values and new technologies. The case of robotic ethics in Europe (in Italian). Metodo, International Studies in Phenomenology and Philosophy, 2(1). 
CSIRO (2015) Telepresence robot for museums. Commonwealth Scientific and Industrial Research Organisation, Australia.

http://www.csiro.au/Organisation-

Structure/Flagships/Digital-Productivity-and- ServicesFlagship/Smart-secure- infrastructure/MuseumRobotCase-study.aspx (retrieved 12 March 2015).

D. M. (2001) Document of guidelines on technical and scientific criteria and on standard of functioning and development of museums (in Italian). Art. 150, comma 6, del D.L. no. 112, 1998. G.U. October 19, no. 244, S. $\mathrm{O}$.

Droids Company (2015) http://www.droidscompany.com/droidlomnynorio/index.html (retrieved 12 March 2015).

Epstein, S. L. (2015) Wanted: collaborative intelligences. Artificial Intelligence, vol. 221, April. Elsevier.

Ermacora G., Toma A., Rosa S., (2015), Fly4SmartCity: a Cloud Robotics Service for Smart City applications", (submitted at Journal of Ambient Intelligent and Smart Environments).

Falconer, J. (2013) Honda's ASIMO get a new job at museum. IEEE Spectrum, 9 July. http://spectrum.ieee.org/automaton/robotics/human oids/honda-asimo-humanoid-robot-gets-new-job-atmuseum (retrieved 28 June 2015)

Germak, C. (2014) from the interview of Strappavecchia, M. C. Robotics at museums (in Italian). L'indro, 17 November. http://www.lindro.it/0cultura/2014-11-17/158271-robotica-musei (retrieved 12 March 2015).

Guizzo, E. (2011) Cloud Robotics: Connected to the cloud, Robot get smarter, IEEE Spectrum, http://spectrum.ieee.org/automaton/robotics/robotics - software/cloud robotics (retrieved 24 January 2011).

Hogan, T., Goveas, D., Noonan, R., \& Twomey, L. (2015) Tarascope: controlling remote telescope through tangible interaction. TEl'15, January 16- 19, Stanford, CA, USA.

Ippoliti, E. (2011) Digital media for the cultural heritage fruition (in Italian). Disegnarecon, 4(8).
ISO (2011) Ergonomics of human-system interaction guidance on World Wide Web user interfaces. ISO 9241-151:2008, 17 September.

http://www.iso.org/iso/iso_catalogue/catalogue_tc/c

Istat (2013) Museums, Archeological Areas and Monuments in Italy. Socio-demographic and Environmental Statistics Directorate, Italy, 5 December. $\quad$ http://www.istat.it/en/archive/106183 (retrieved 28 June 2015).

Macaluso, I., Ardizzone, E., Chella, A., Cossentino, M., Gentile, A., Gradino, R., Infantino, I., Liotta, M., Rizzo, R., \& Scardino, G. (2005) Experiences with cicerobot, a museum guide cognitive robot. Advances in Artificial Intelligences, Lecture Notes in Computer Science, vol. 3673. Springer.

McDonnell, I. (2001) The role of the tour guide in transferring cultural understanding. Working Paper No. 3, School of Leisure, Sport and Tourism, Sydney, Australia.

Nourbakhsh, I., Bobenage, J., Grange, S., Lutz, R., Meyer, R., \& Soto, A. (1999) An affective mobile robot educator with a full-time job. International Journal of Artificial Intelligence, 114, Elsevier.

Oiron (2015) Norio: Un robot pour entrer dans l'histoire (in French). Château d'Oiron, National Centre for Monuments, France. http://www.oiron.fr/noriorobot-de-visite.html (retrieved 12 March 2015).

Pirrelli, M. (2012) The hidden art deposits (in Italian). Commenti\&Inchieste, $\|$ Sole 24 Ore. http://www.ilsole24ore.com/art/commenti-eidee/2012-03-30/giacimenti-nascosti-arte064018.shtml?uuid=AbIDg9FF (retrieved 12 March 2015).

Proctor, N. (2011) The Google Art Project: a new generation of museums on the web? Curator: The Museum Journal, 54(2), April.

Quigley, M., Conley, K., Gerkey, B., Faust, J., Foote, T., Leibs, J., Berger E., Wheeler R. e Ng, A. Y. (2009, May). ROS: an open-source Robot Operating System. In ICRA workshop on open source software (Vol. 3, No. 3.2, p. 5).

Salvini, P., Laschi, C., \& Dario, P. (2010) Design for acceptability: improving robots' coexistence in human 
society. International Journal of Social Robotics, Springer.

Schraft, R. D., Graf, B., Traub, A., \& John, D. (2001) A mobile robot platform for assistance and entertainment. International Journal of Industrial Robot, 28(1). MCB University Press.

Suchy, S. (2006) Museum management: emotional value and community engagement. Intercom 2006, 24 November, Taipei, Taiwan.

Sylaiou, S., Killintzis, V., Paliokas, I., Mania, K., \& Patias, P. (2014) Usability evaluation of virtual museums' interfaces visualization technologies. VAMR 2014, Part II, Lecture Notes in Computer Science, vol. 8526. Springer.

Tate (2015) After Dark. Tate Britain, London, UK. http://www.tate.org.uk/whats-on/tate-britain/specialevent/after-dark (retrieved 12 March 2015).

Thrun, S., Bennewitz, M., Burgard, W., Cremers, A. B., Dellaert, F., Fox, D., Hahnel, D., Rosenberg, C., Roy, N., Schulte, J., \& Schulz, D. (1999) Minerva: a tour-guide robot that learns. KI-99, Advances in Artificial Intelligences, Lecture Notes in Computer Science, vol. 1701. Springer.

Tresset, P. A., \& Laymarie, F. F. (2012) Sketches by Paul the robot. In D. Cunningham \& D. House (eds.), Computational Aesthetics in Graphics, Visualization and Imaging.

Willeke T., Kunz C., Nourbakhsh I., (2001) The history of the Mobot museum robot series: an evolutionary study. Flairs - 01. Proceedings, AAAI.

\section{BIOGRAPHICAL INFORMATION}

CLAUDIO GERMAK Architect and designer, full professor of Industrial Design at Politecnico di Torino, Deputy Head of DAD Department of Architecture \& Design. $\mathrm{He}$ is a researcher of design-oriented production systems, on which he published among 107 articles and monographs, curated exhibitions and researches. Expert in product design and process, he developed products, patents and received 4 design awards for industrial components and 2 Mentions ADI Compasso d'Oro. Today he leads the team HELP Politecnico di Torino, active in the fields of user experience and interaction design for transport systems and service robotics. Founder, and board member, of SID - Italian Scientific Society of Design.

MARIA LUCE LUPETTI She achieved a B.Sc. in Industrial Design at the ISIA Roma Design and a M.Sc. in Ecodesign at Politecnico di Torino. She worked as Research fellow on HRI and UX design, for 8 months at Jol CRAB, joint laboratory of Telecom Italia in collaboration with Politecnico di Torino. She is currently a first year PhD student at the Department of Management, Production and Design (DIGEP) of Politecnico di Torino, working on Design Research for Edutainment Robotics.

LUCA GIULIANO He achieved a B.Sc. in Industrial Design at the Politecnico di Milano and a M.Sc. in Ecodesign at Politecnico di Torino. He worked as Research fellow on $\mathrm{HRI}$ and UX design, for 1 year at Jol CRAB, joint laboratory of Telecom Italia in collaboration with Politecnico di Torino. He is currently a second year PhD student at the Department of Management, Production and Design (DIGEP) of Politecnico di Torino, working on Robotics for Cultural heritage.

MIGUEL E. KAOUK NG He received a B.Sc. in Electrical Engineering from Universidad Central de Venezuela and M.Sc. in Mechatronics Engineering in 2006 from Politecnico di Torino as a double degree agreement. In 2010 he achieved his $\mathrm{PhD}$ in Mechatronic Engineering from Politecnico di Torino. Since August 2014 he is research assistant at DAUIN (Department of Control and Computer Engineering) at Politecnico di Torino. His main research areas involve Mobile Robot Navigation (localization, mapping, SLAM and path planning algorithms) and Automation Systems. 